\title{
Feasibility study of earthquake early warning in Tehran, Iran
}

\author{
S. Enferadi • Z. H. Shomali • A. Niksejel
}

Received: 19 February 2021 / Accepted: 11 May 2021 / Published online: 23 May 2021

(C) The Author(s) 2021

\begin{abstract}
In this study, we examine the scientific feasibility of an Earthquake Early Warning System in Tehran, Iran, by the integration of the Tehran Disaster Mitigation and Management Organization (TDMMO) accelerometric network and the PRobabilistic and Evolutionary early warning SysTem (PRESTo). To evaluate the performance of the TDMMO-PRESTo system in providing the reliable estimations of earthquake parameters and the available lead-times for The Metropolis of Tehran, two different approaches were analyzed in this work. The first approach was assessed by applying the PRESTo algorithms on waveforms from 11 moderate instrumental earthquakes that occurred in the vicinity of Tehran during the period 2009-2020. Moreover, we conducted a simulation analysis using synthetic waveforms of 10 large historical earthquakes that occurred in the vicinity of Tehran. We demonstrated that the six worst-case earthquake scenarios can be considered for The Metropolis of Tehran, which are mostly related to the historical and instrumental events that occurred in the southern, eastern, and western parts of Tehran. Our results indicate that the TDMMO-PRESTo system could provide reliable and sufficient lead-times of about 1 to $15 \mathrm{~s}$ and maximum lead-times of about 20 s for civil protection purposes in The Metropolis of Tehran.
\end{abstract}

S. Enferadi $\cdot$ Z. H. Shomali $(\bowtie) \cdot$ A. Niksejel Institute of Geophysics, University of Tehran, Tehran, Iran e-mail: shomali@ut.ac.ir

Z. H. Shomali

Department of Earth Sciences, Uppsala University, Uppsala, Sweden
Keywords Earthquake Early Warning System(EEWS) · PRESTo · TDMMO · The Metropolis of Tehran

\section{Introduction}

Advances in earthquake detection and recent developments in sensor technology have made possible shortterm earthquake forecasting in the form of Earthquake Early Warning System (EEWS). Nowadays, the population growth and the concentration of infrastructure in metropolitan areas have increased their vulnerability to earthquakes. Thanks to EEWS, human losses and destructive effects of earthquakes may decrease. However, adequate plans and proper training are required for the population to be warned and to be able to react accordingly. Therefore, one of the most efficient ways to reduce the loss of life caused by a potentially destructive earthquake in metropolitan areas such as Tehran is the use of the EEWS.

The Iranian plateau is a wide zone of compressional deformation along the active Alps-Himalayan seismic belt, resulting from the convergence of the Eurasian and Arabian plates. The Iranian plateau is one of the most active seismic zones in the world (Tchalenko et al. 1974; Jackson and McKenzie 1984). Part of deformation in the Iranian plateau is taken up in the Alborz Mountain Belt, which is located in the northern part of the Iranian plateau. The Alborz Mountain Belt, with a length of $600 \mathrm{~km}$ and a width of $100 \mathrm{~km}$, contains many active faults with high potential for producing devastating earthquakes (Berberian et al. 1983; Moinfar et al. 
1994; Berberian and Yeats 1999). Tehran, as the political, commercial, and economic capital of Iran, is located on the southern edge of the central Alborz Mountain Belt.

Tehran hosts many active faults, including the Mosha reverse fault, the North Tehran thrust fault, and the North and the South Rey reverse faults (Fig. 1) (Berberian et al. 1983; Moinfar et al. 1994; Berberian and Yeats 1999). Based on historical documents, the Mosha fault experienced several large earthquakes during the historical times (i.e., in $958 M_{S}=7.7,1665 M_{S}=6.5$, and 1830 $M_{s}=7.1$ ). The return period of these earthquakes is estimated to be $\sim 165$ years and the last devastating historical earthquake in Tehran region occurred in 1830 about $80 \mathrm{~km}$ from Tehran; thus, more than 190 years have passed since this event (Ambraseys and Melville 1982; Berberian and Yeats 1999). In recent years, several moderate events $\left(4.0 \leq M_{L} \leq 5.2\right)$ occurred in the study area due to the activity of Mosha, Ray, and North Tehran faults. The instrumental seismicity (from the catalog of Iranian Seismological Center (IRSC)) and the historical seismicity in the study area are listed in Tables 1 and 2 (Ambraseys and Melville 1982). Moinfar et al. (1994) assumed that the Mosha fault may be the source of a devastating earthquake in Tehran in the future. Recently, a moderate earthquake occurred in Damavand region on 2020 May 07 ( $M_{L}$ 5.0) (Table 1). The epicentral distance from this earthquake to the eastern edge of Tehran is estimated to be $\sim 57 \mathrm{~km}$. The recent Damavand earthquake, which caused more than 50 aftershocks $\left(M_{L}<5.0\right)$, apparently occurred on the Mosha fault.

The main aim of this study is to explore the feasibility of an EEWS in Tehran, by the integration of the Tehran Disaster Mitigation and Management Organization (TDMMO) network (https://tdmmo.tehran.ir/) and the PRobabilistic and Evolutionary early warning SysTem (PRESTo) software system (Satriano et al. 2011). To this purpose, we followed Picozzi et al. (2015a), and evaluated this feasibility study by analyzing waveforms from 11 moderate instrumental earthquakes that occurred in the last decade in the vicinity of Tehran which have been recorded by the TDMMO network. Furthermore, we followed Satriano et al. (2011) and Picozzi et al. (2015b), and extended our analysis to larger areas and conducted a simulation analysis using synthetic waveforms of 10 large historical earthquakes that occurred in the vicinity of Tehran. Then, we assessed the performance of the TDMMO-PRESTo system by considering the 10 scenarios of historical earthquakes.

\section{Earthquake Early Warning System}

EEWS is one of the modern and operational disciplines in seismology, which have experienced a wide implementation in many countries, especially in the active seismic regions. EEWS is able to detect and screen earthquakes and provide a few seconds of warning to target areas, before the arrival of the destructive S- and surface waves (Satriano et al. 2010; Zollo et al. 2014). In recent years, a large number of EEWS have been implemented or are being tested in many countries. In general, the EEWS may be (1) regional- or network-based, and (2) onsite or station-based methods (Nakamura 1988). In a regional EEWS, the dense seismic network is located near the earthquake source area, where the targets are far away from it. On the other hand, on-site EEWS is based on the use of the initial portion of the P-wave, where the target sites are near to the fault zones (Nakamura 1988; Odaka et al. 2003; Satriano et al. 2010). The main difference between these two approaches is the lead-time (LT). The LT is the time difference between the issue of the early warning message and the arrival of the damaging waves for a given site. Hence, the LT for the regional EEWS can be relatively long, while the LT for the on-site EEWS is quite short. Another key parameter defined for EEWS is the blind zone (BZ). The BZ shows the areas where no LT is available and no practical early warning is possible due to the presence of destructive waves (Zollo et al. 2014; Picozzi et al. 2015a).

In recent years, Zollo et al. (2010) implemented a new probabilistic approach as a threshold-based method, by integrating regional and on-site approaches, called the PRobabilistic and Evolutionary early warning SysTem (PRESTo), in Southern Italy on the Irpinia Seismic Network (ISNet). Furthermore, this integrated approach has increased the accuracy of calculations, especially in areas where the residential structures are close to the active faults. PRESTo is an open source software platform for EEW that continually processes real-time streams of ground motion to detect the P-wave arrival. PRESTo uses different algorithms to detect Pwave arrival, estimate source parameters (event location and magnitude), and predict the ground shaking by using attenuation functions (see, e.g., Satriano et al. 2008; Zollo et al. 2009, 2010; Satriano et al. 2010, 2011; Colombelli et al. 2012; Zollo et al. 2014; Picozzi et al. 2015a, b). 


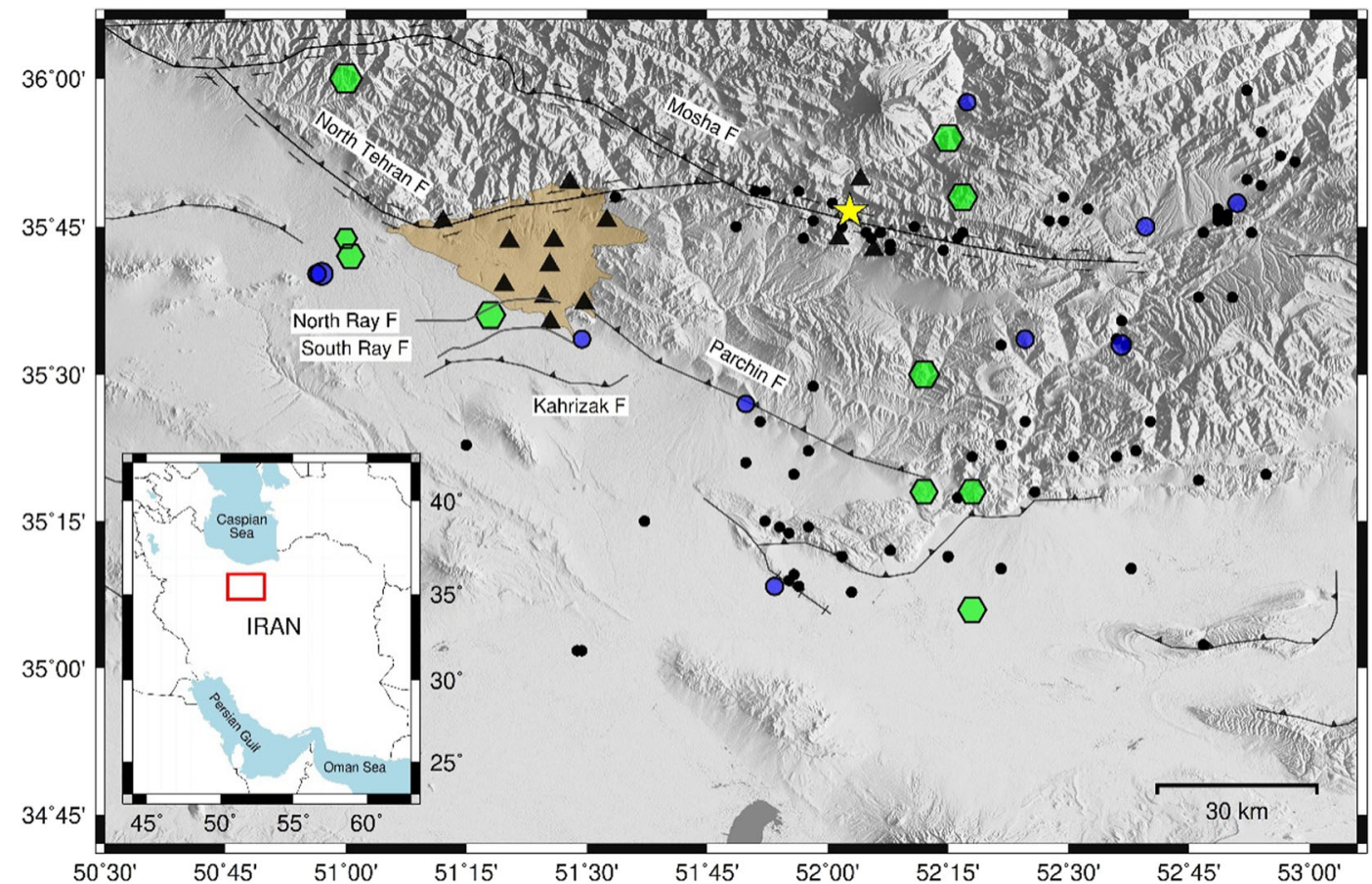

Fig. 1 Map showing the location of instrumental earthquakes with magnitudes between $4.0 \leq M_{L} \leq 5.2$ (blue circles) and instrumental earthquakes with magnitudes between $3.0<M_{L}<4.0$ (black circles) during the period 2009-2020 (from the IRSC catalog), historical earthquakes (green hexagons) (Ambraseys and Melville

\section{Dataset}

The TDMMO network was operated in Tehran region in a collaboration with Japan International Cooperation Agency (JICA) in 2009. This network consists of 14 strong motion stations with an average spacing of about
1982), and TDMMO network stations (black triangles) in the Tehran region (brown shaded region). The black lines illustrate the major faults. The yellow star represents the epicenter of the 2020 May $07 M_{L}$ 5.0 Damavand earthquake

$30 \mathrm{~km}$ between the stations, which are designed to completely cover Tehran and its surroundings. It is worth noting that 4 stations of the TDMMO network are located in the active seismic areas in the vicinity of Tehran with the aim of EEW, and other stations are placed within The Metropolis of Tehran with the aim

Table 1 Location and origin time of the studied instrumental earthquakes from the IRSC catalog

\begin{tabular}{llllllll}
\hline Year & Month & Day & Origin time & Latitude $\left(^{\circ}\right)$ & Longitude $\left(^{\circ}\right)$ & Depth $(\mathrm{km})$ & Magnitude $\left(M_{L}\right)$ \\
\hline 2009 & 10 & 17 & $10: 53: 56$ & 35.56 & 51.49 & 12.0 & 4.0 \\
2010 & 01 & 20 & $05: 20: 07$ & 35.79 & 52.85 & 3.5 & 4.2 \\
2011 & 02 & 20 & $11: 22: 16$ & 35.45 & 51.83 & 5.0 & 4.0 \\
2014 & 08 & 16 & $23: 55: 57$ & 35.96 & 52.29 & 12.0 & 4.0 \\
2015 & 08 & 13 & $18: 42: 13$ & 35.14 & 51.89 & 5.0 & 4.1 \\
2015 & 08 & 25 & $17: 36: 33$ & 35.55 & 52.61 & 12.8 & 4.6 \\
2017 & 12 & 20 & $19: 57: 37$ & 35.67 & 50.95 & 5.9 & 5.2 \\
2017 & 12 & 26 & $21: 24: 34$ & 35.67 & 50.94 & 5.7 & 4.2 \\
2018 & 01 & 15 & $13: 50: 03$ & 35.75 & 52.66 & 5.2 & 4.2 \\
2018 & 04 & 01 & $18: 26: 21$ & 35.56 & 52.41 & 52.05 & 4.1 \\
2020 & 05 & 07 & $20: 18: 21$ & 35.78 & 5.0 & \\
\hline
\end{tabular}


Table 2 Location and date of the studied historical earthquakes (Ambraseys and Melville 1982)

\begin{tabular}{lllll}
\hline Year & Latitude $\left(^{\circ}\right)$ & Longitude $\left(^{\circ}\right)$ & Depth $(\mathrm{km})$ & Magnitude $\left(M_{s}\right)$ \\
\hline 743 & 35.50 & 52.20 & 14 & 7.2 \\
855 & 35.60 & 51.30 & 12 & 7.1 \\
864 & 35.73 & 51.00 & 12 & 5.3 \\
958 & 36.00 & 51.00 & 9 & 7.7 \\
1665 & 35.70 & 51.01 & 10 & 6.5 \\
1687 & 35.30 & 52.30 & 11 & 6.5 \\
1809 & 35.30 & 52.20 & 12 & 6.5 \\
1825 & 35.10 & 52.30 & 14 & 6.7 \\
1830 & 35.80 & 52.28 & 8 & 7.1 \\
1868 & 35.90 & 52.25 & 9 & 7.2 \\
\hline
\end{tabular}

of casualty estimation. Data recording at the stations within The Metropolis of Tehran is based on the use of CMG-5T broadband accelerometer sensors owned by Guralp Company. These sensors are equipped with GSL CMG-DM24 digitizer and GSL CMG-EAM module.

In this study, we have considered 14 stations of the TDMMO network that managed to record 11 moderate instrumental earthquakes in the last decade. Figure 1 shows the distribution of the used stations of TDMMO network and selected earthquakes. Thus, this study was done only considering the technical and geometrical specifications of the TDMMO network, assuming that the hardware and software of the TDMMO network would provide real-time access.

\section{Methods}

This study is based on two main approaches: (1) the analyses based on instrumental seismicity (observed data), and (2) the analyses based on historical seismicity (synthetic data). First, we optimized and tuned all input parameters implemented in PRESTo for the study area including the algorithms used for estimations of location and magnitude (e.g., the RTLoc and RTMag), the attenuation relationships, and crustal velocity model. To achieve the goals of this study, we selected the crustal velocity model developed by Abbassi et al. (2010) for Tehran region (Table 3). After exhaustive tests, using observed data, the empirical attenuation relationships proposed by Nowroozi (2010) and Soghrat and Ziyaeifar (2017) were adapted as the optimal model for Tehran region. We also used the empirical attenuation relationship between $\log (\mathrm{Pd})$ and earthquake parameters (hypocentral distance and magnitude) obtained by Nazeri et al. (2017). Note that the IRSC catalog reports the magnitude in the modified Nuttli scale $\left(M_{N}\right)$. Hence, we converted $M_{N}$ to $M_{L}$ using the equation proposed by Nazeri et al. (2017).

\subsection{Analyses based on instrumental seismicity}

The main strategy of the analyses based on observed data is the use of 14 stations of TDMMO network for EEW purposes. The performance of the system was evaluated by applying the PRESTo algorithms on waveforms from 11 moderate instrumental earthquakes that occurred in the vicinity of Tehran. Furthermore, the efficiency of TDMMO-PRESTo EEWS was assessed in providing the following parameters by considering the network's performance and using the first few seconds of the arriving P-waves: (1) the estimation of earthquake parameters (location and magnitude), (2) the time needed to perform associated calculations (time

Table 3 The crustal velocity model used for our simulations with $\mathrm{Vp} / \mathrm{Vs}$ ratio approximately 1.73 (Abbassi et al. 2010)

\begin{tabular}{lll}
\hline Depth range $(\mathrm{km})$ & P-velocity $(\mathrm{km} / \mathrm{s})$ & S-velocity $(\mathrm{km} / \mathrm{s})$ \\
\hline 0.0 & 5.6 & 3.3 \\
2.0 & 5.4 & 3.1 \\
3.0 & 5.8 & 3.4 \\
7.0 & 6.1 & 3.5 \\
16.0 & 6.3 & 3.1 \\
24.0 & 6.4 & 3.6 \\
\hline
\end{tabular}


of the estimation), and (3) the distribution of LT and radii of the $\mathrm{BZ}$.

To this purpose, the validity and robustness of the obtained results were assessed in two different cases: (1) when the first estimation of location/magnitude is calculated by TDMMO-PRESTo system, while only three stations have been triggered, and (2) when the optimal estimation of location/magnitude is calculated by TDMMO-PRESTo system, while more than three stations have been triggered. According to our thorough analyses, the optimal estimate of the parameters is controlled by two major factors: (I) when the earthquake location is estimated with an error in epicentral less than $10 \mathrm{~km}$, and (II) when the magnitude estimation is associated with an uncertainty interval of less than \pm 0.5 magnitude units. It is worth noting that the time of the estimation (TE) is the seconds needed by the TDMMOPRESTo system for the first or optimal estimation of location/magnitude by three and more than three triggered stations, respectively. Note that the reference results for the location and magnitude estimates are taken from the IRSC catalog.

\subsection{Analyses based on historical seismicity}

In order to extend our analysis to regions that have experienced historical earthquakes, the performance of the TDMMO-PRESTo system was assessed based on synthetic simulations. Synthesis of seismograms was calculated using Axitra software package, a numerical code of Coutant (1989). To improve the accuracy of the obtained results, the Axitra program was first optimized by simulation of waveforms of the 2009 October $17 M_{L}$ 4.0 Rey earthquake, where we have observational signals at different stations as well as source parameters obtained by Yaminifard et al. (2012). Then, playbacks of the observed and synthetic waveforms were run offline in PRESTo for 2009 October $17 M_{L} 4.0$ Rey earthquake. Our analyses indicate that the location and magnitude errors obtained from synthetic data are in good agreement with running PRESTo playback on observed data recorded by the TDMMO network. Figure 2 shows an example of a plot between observed and synthetic signals for three components of D161 station from the 2009 October $17 M_{L} 4.0$ Rey earthquake. Note that there is a good agreement between the observed and synthetic signals as shown in Fig. 2.

Then, the synthetic data were calculated for 10 large historical earthquakes that occurred in the vicinity of
Tehran. Based on reliable documents, the only available information from historical earthquakes are parameters such as magnitude $\left(M_{S}\right)$, location (latitude and longitude), and depth with large uncertainty (Ambraseys and Melville 1982). Due to the lack of near-field acceleration records from historical and large instrumental earthquakes, we adopted the point source assumption for historical earthquakes. Moreover, because most of the EEWS software, including PRESTo, implicitly adopts the point source assumption (Picozzi et al. 2015a), the finite extent of the fault and rise time for large historical events were not considered in this study. Finally, the synthetic seismograms were calculated using seismic moment $\left(M_{0}\right)$ for a range of possible focal mechanisms for the study area. Note that the $M_{0}$ was calculated using the Purcaru and Berckhemer (1978) relationship.
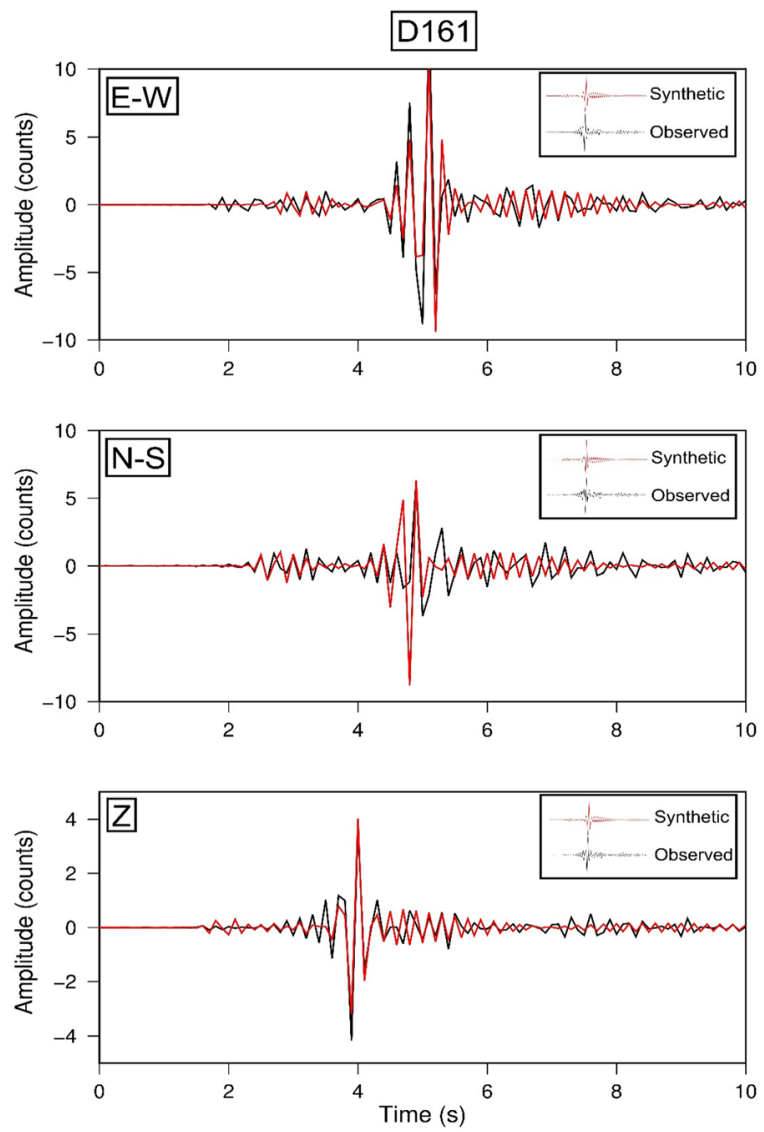

Fig. 2 An example of a plot between observed (black) and synthetic signals (red) for three components of D161 station from the 2009 October $17 M_{L} 4.0$ Rey earthquake. The traces are started from the origin time. The vertical axis shows the amplitude in units of counts. All the synthetic signals are band-pass filtered between 0.1 and $4.0 \mathrm{~Hz}$ 
Fig. 3 Results of the PRESTo playbacks with TDMMO network recordings of 11 moderate instrumental earthquakes that occurred in the last decade in the vicinity of Tehran. a The location of analyzed instrumental earthquakes (blue circles), the estimated location by TDMMOPRESTo system (red stars), the epicenter of Damavand earthquake (yellow star), and the location of TDMMO network stations (black triangles). b Error in epicentral estimation by only three triggered stations. c Same as Fig. $3 b$ but by more than three triggered stations. d Error in magnitude estimation using only three triggered stations. Mew is the estimated magnitude by the TDMMO-PRESTo system and Mtrue is the real magnitude reported by IRSC. e Same as Fig. $3 \mathrm{~d}$ but by more than three triggered stations. Seconds needed by the TDMMO-PRESTo system for the first (f) or optimal estimation (g) a)

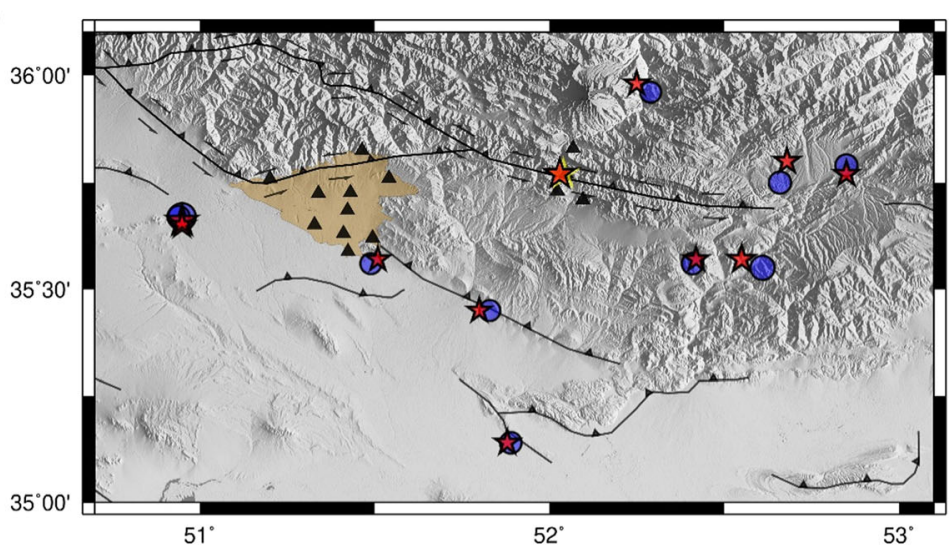

b)

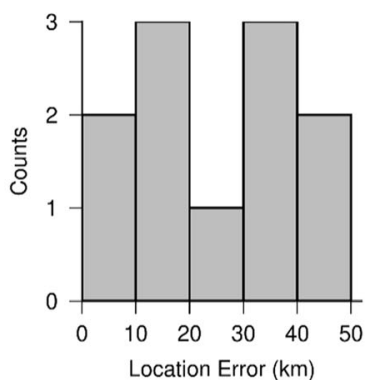

c)

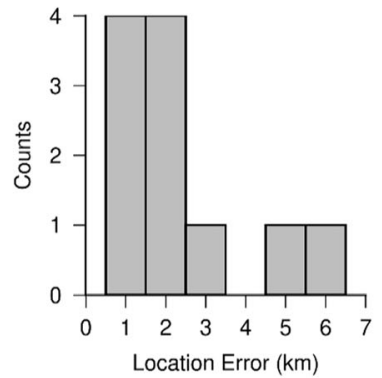

d)

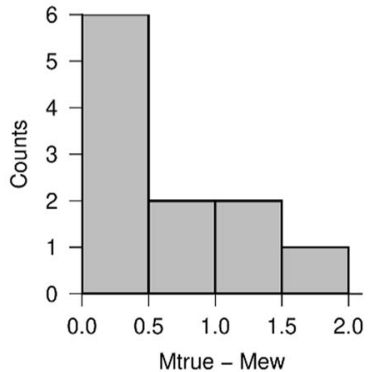

e)

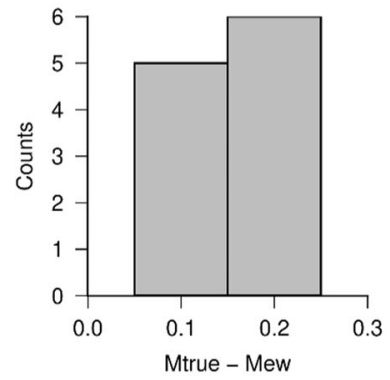

f)

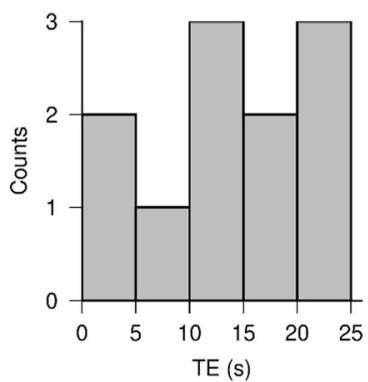

g)

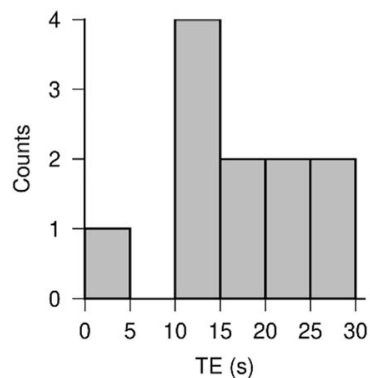

Next, PRESTo algorithms were applied on the obtained waveforms from 10 large historical earthquakes that occurred in the vicinity of Tehran. Furthermore, the performance of the TDMMO-PRESTo EEWS was evaluated in providing the reliable estimations of earthquake parameters and distribution of LT for The Metropolis of Tehran.

\subsection{The distribution of LT and BZ}

The incorrect estimation of earthquake parameters is one of the key factors that affect the performance of EEWS in the reduction of earthquake casualties. The more accurate the earthquake parameters' estimations are, the longer the estimated LT and the less the radii of the BZ would be. 
Table 4 The performance of the system based on observed data for the studied instrumental earthquakes considering three and more than three stations

\begin{tabular}{|c|c|c|c|c|}
\hline $\begin{array}{l}\text { Instrumental } \\
\text { earthquakes } \\
\text { (year) }\end{array}$ & $\begin{array}{l}\text { Number of } \\
\text { triggered } \\
\text { stations }\end{array}$ & $\begin{array}{l}\text { Error of } \\
\text { location } \\
(\mathrm{km})\end{array}$ & $\begin{array}{l}\text { Error of } \\
\text { magnitude } \\
\text { (unit) }\end{array}$ & $\begin{array}{l}\mathrm{TE} \\
\text { (s) }\end{array}$ \\
\hline \multirow[t]{2}{*}{ 2017-12-20 } & 3 & 2 & 0.1 & 4 \\
\hline & 3 & 2 & 0.1 & 4 \\
\hline \multirow[t]{2}{*}{$2017-12-26$} & 3 & 16 & 0.0 & 10 \\
\hline & 6 & 2 & 0.2 & 11 \\
\hline \multirow[t]{2}{*}{ 2009-10-17 } & 3 & 2 & 0.1 & 3 \\
\hline & 3 & 2 & 0.1 & 3 \\
\hline \multirow[t]{2}{*}{ 2011-02-20 } & 3 & 45 & 1.4 & 8 \\
\hline & 7 & 1 & 0.2 & 11 \\
\hline \multirow[t]{2}{*}{ 2015-08-13 } & 3 & 10 & 0.3 & 5 \\
\hline & 4 & 1 & 0.2 & 10 \\
\hline \multirow[t]{2}{*}{ 2018-04-01 } & 3 & 15 & 0.3 & 16 \\
\hline & 10 & 1 & 0.2 & 20 \\
\hline \multirow[t]{2}{*}{ 2010-01-20 } & 3 & 35 & 0.5 & 20 \\
\hline & 9 & 2 & 0.1 & 26 \\
\hline \multirow[t]{2}{*}{$2014-08-16$} & 3 & 35 & 1.5 & 16 \\
\hline & 5 & 3 & 0.2 & 17 \\
\hline \multirow[t]{2}{*}{$2015-08-25$} & 3 & 30 & 0.4 & 20 \\
\hline & 5 & 6 & 0.1 & 23 \\
\hline \multirow[t]{2}{*}{ 2018-01-15 } & 3 & 40 & 1.2 & 20 \\
\hline & 10 & 5 & 0.2 & 26 \\
\hline \multirow[t]{2}{*}{$2020-05-07$} & 3 & 10 & 0.7 & 7 \\
\hline & 6 & 1 & 0.1 & 11 \\
\hline
\end{tabular}

Since the BZ experiences mainly high shaking, if EEWS is used correctly, there would be significant effects on reducing the casualties and regional losses. The BZ depends on the geometry of the network with respect to an event, the telemetry (e.g., data latency), and associated calculations. In PRESTo software platform, the BZ is defined by the sum of three delays: (1) a delay time for the first estimation of location and magnitude, (2) a delay time for the telemetry and computation, and (3) a delay time for issuing the first warning. Finally, multiplying the sum of these three time delays by the average S-wave velocity will determine the radii of the BZ (Picozzi et al. 2015a). In order to calculate the distribution of LT and the radii of the $\mathrm{BZ}$, we considered distribution of different points as the target sites in the PRESTo settings within and around The Metropolis of Tehran and calculated the LT for each of these points accordingly.

\section{Results}

\subsection{Performance of TDMMO-PRESTo on observed data}

Figure 3 demonstrates the overall performance of the TDMMO-PRESTo system for the playbacks of observed data from 11 moderate instrumental earthquakes that occurred in the vicinity of Tehran (Fig. 3a). The results of the performance are listed in Table 4, where three and more than three stations are triggered. Proper density of seismic stations is one of the key factors in determining the performance of an EEWS. Therefore, there is a direct relation between the number of stations and the accuracy of estimation of earthquake parameters.

Figure $3 \mathrm{~b}$ shows the performance of the TDMMOPRESTo system for only three triggered stations. Concerning the first estimation of location, we observe that for most of the analyzed earthquakes, the system could not provide reliable results. However, Fig. 3c indicates that the system, while relying on more than three stations, provides accurate estimation of earthquake location with an error in epicentral less than $10 \mathrm{~km}$ from the location provided in the IRSC catalog.

In Fig. 3d, we observe that the system in order to estimate the first magnitude, while relying on only three stations, provides reliable estimation of earthquake magnitude in 8 cases out of the 11 analyzed earthquakes (i.e., 72\%). Furthermore, Fig. 3e shows that the TDMMO-PRESTo system, when more than three stations are triggered, provides reliable estimation of earthquake magnitude in all of the analyzed earthquakes. Note that the estimation of earthquake magnitude by the TDMMO-PRESTo system is only reliable when associated with an uncertainty interval of less than \pm 0.5 magnitude units. Obviously as demonstrated in Fig. $3 \mathrm{f}$ and $\mathrm{g}$, the TE increases with increase in the number of the triggered stations. Furthermore, increasing the number of triggered stations could decrease the estimated LT.

In Figs. 4 and 5, we present the comparison between the distribution of the LT and the BZ for The Metropolis of Tehran by considering the 11 scenarios of instrumental earthquakes and the TDMMO network configuration. In the same figures, we observe that the TDMMOPRESTo system could provide sufficient LT of about 1 to 20 s. Note that Fig. 5 is related to the 2020 May $07 M_{L}$ 5.0 recent Damavand earthquake. We have to emphasize that the calculated LT for The Metropolis of Tehran 
Fig. 4 Distribution of the LT and radii of the BZ for The Metropolis of Tehran. The location of 10 instrumental earthquakes (blue circles), the estimated location by the TDMMO-PRESTo system (red stars), the BZ (red area), and the distribution of LT (i.e., black lines at $1,3,5,7 \mathrm{~s}$, etc.) (a)

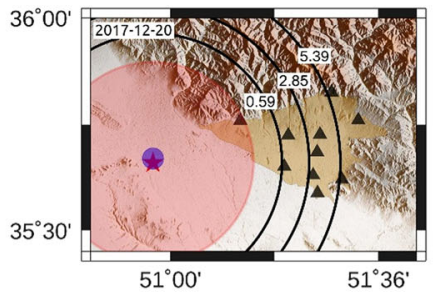

(b)

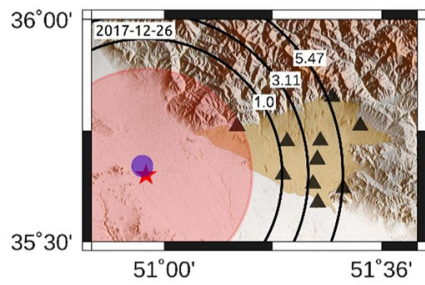

(c)

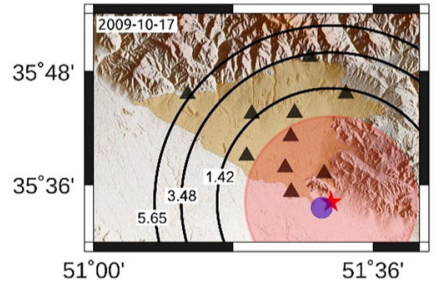

(d)

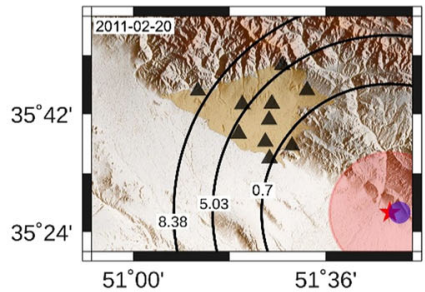

(e)

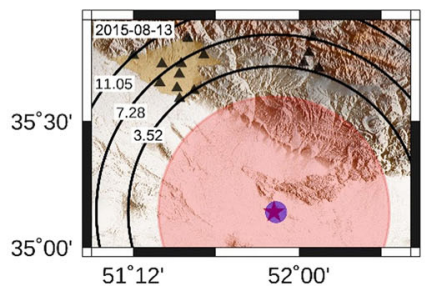

(f)

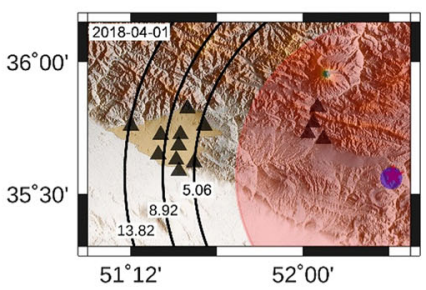

(g)

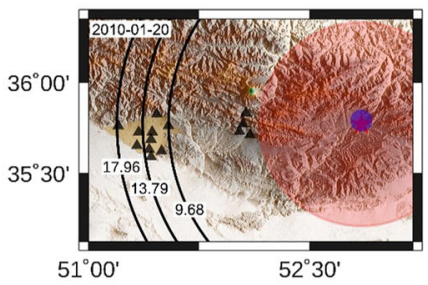

(h)

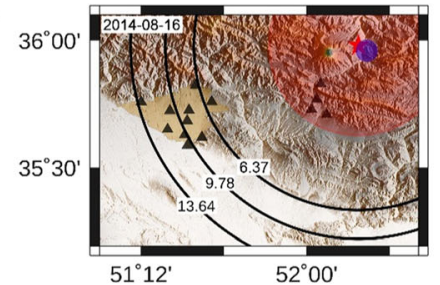

(i)

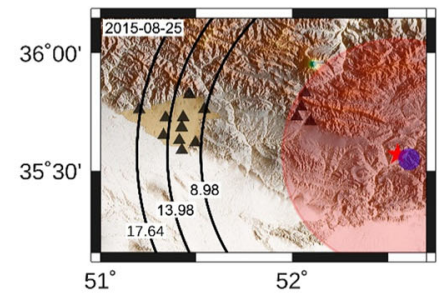

(j)

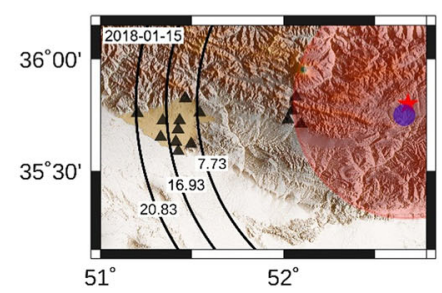

are based on optimal estimation of earthquake parameters by the TDMMO-PRESTo system and varies for each event, depending essentially on the network's geometry and the quality of the data (Table 4).

\subsection{Performance of TDMMO-PRESTo on synthetic data}

Figure 6 shows the results of the performance for the analyses based on synthetic data by considering the 10 scenarios of historical earthquakes for The Metropolis of Tehran (Fig. 6a). In Fig. $6 \mathrm{~b}$ to g, we observe that when only three triggered stations are used, the first estimations of earthquake parameters are not reliable because their corresponding uncertainties are large. Moreover, in the case where more than three stations are triggered, the system provides reliable estimations of earthquake parameters. Therefore, in case of large events, the TDMMO-PRESTo system could provide, for most of the analyzed earthquakes, significant estimations of the earthquakes' location and magnitude with an error in epicentral less than $10 \mathrm{~km}$ and with an uncertainty interval of less than \pm 0.5 magnitude units, respectively (Table 5). 
Fig. 5 Same as Fig. 4 but for the 2020 May $07 M_{L} 5.0$ Damavand earthquake

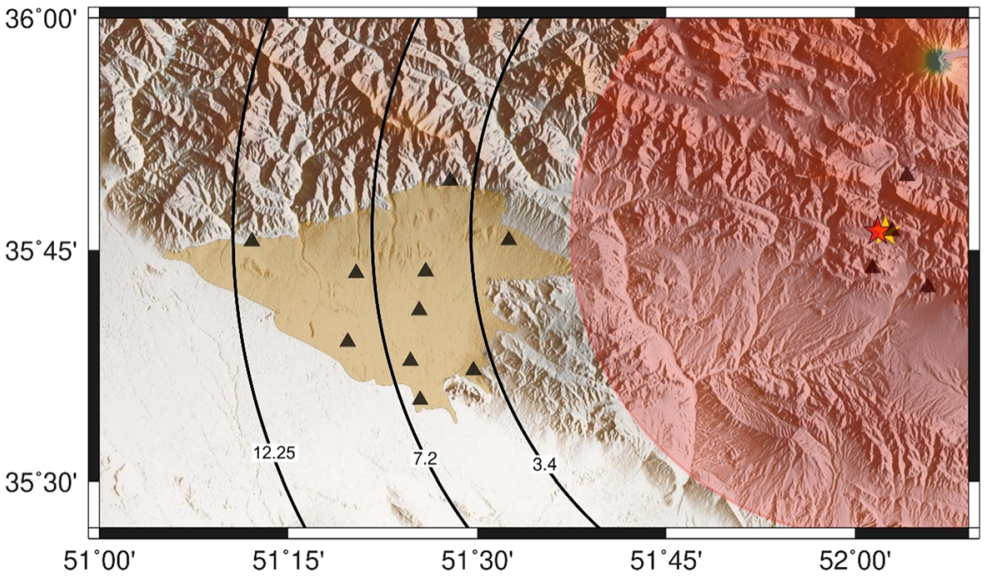

The analyses based on synthetic data demonstrated that the TDMMO network is not dense and the number of TDMMO network stations has a direct effect on the TDMMO-PRESTo performance. However, in Fig. 7, we observe that the system has a high potential to provide the maximum reliable $\mathrm{LT}$ of about $15 \mathrm{~s}$ for vulnerable areas of Tehran.

\section{Discussion}

Most of available EEWS in the world are based on regional or on-site approaches. Nowadays, the combined use of both approaches has increased. The integrated EEWS approach proposed by Zollo et al. (2010) has been synthesized in the PRESTo software package and successfully tested in Southern Italy (Picozzi et al. 2015a). TDMMO is one of the centers in Tehran that has conducted numerous research studies on EEWS in recent years. In this study, we tried to evaluate the feasibility of an EEWS in Tehran, by integrating TDMMO network and PRESTo software platform. Note that our results were obtained by the offline run of the TDMMOPRESTo system and the time required for data telemetry (data latency) was not considered.

The analyses of observed data suggest that due to the network's geometry (i.e., the number and distribution of stations available at each event) and low quality of the data, when only three stations are triggered, the TDMMO-PRESTo system provides reliable estimations of the earthquakes' location and magnitude only in $18 \%$ and $72 \%$ of the cases, respectively (Fig. 3). However, we observed that the system for the cases of three stations could provide fast and reliable estimations of earthquake parameters in some cases such as the 2017 December $20 M_{L} 5.2$ Malard earthquake and the 2009 October $17 M_{L} 4.0$ Rey earthquake. In other words, in these two events the first estimation of location/magnitude was considered the optimal estimation, while only three stations have been triggered (Fig. 4a and c; Table 4). It is worth noting that these two earthquakes were detected quickly, since they were closer to the TDMMO network. Furthermore, our results show that, when more than three stations are used, the performance of the system improves significantly while the obtained LT are reduced.

Due to the lack of historical seismic records, we used synthetic data of historical earthquakes to model the effect of large earthquakes $(M>6.0)$ on a potential EEWS in Tehran. Note that we adapted the point source model for large historical events to extend our feasibility analyses to larger areas of Tehran. Even though the point source assumption may not be an accurate assumption for large historical events, we decided to use the point source assumption to evaluate the TDMMO network capability in providing the reliable estimations of earthquake parameters and available LT for The Metropolis of Tehran. The analyses of synthetic data confirmed that for most of the analyzed historical earthquakes, the system could not provide reliable estimations of earthquake parameters, using only three triggered stations. However, the system provides an accurate estimation of earthquake location and magnitude in the case of the $855 M_{s} 7.1$ Ray earthquake, while relying on only three stations (Fig. 6; Table 5). It is necessary to 
Fig. 6 Same as Fig. 3 but for 10 large historical earthquakes that occurred in the vicinity of Tehran (green hexagons) a)

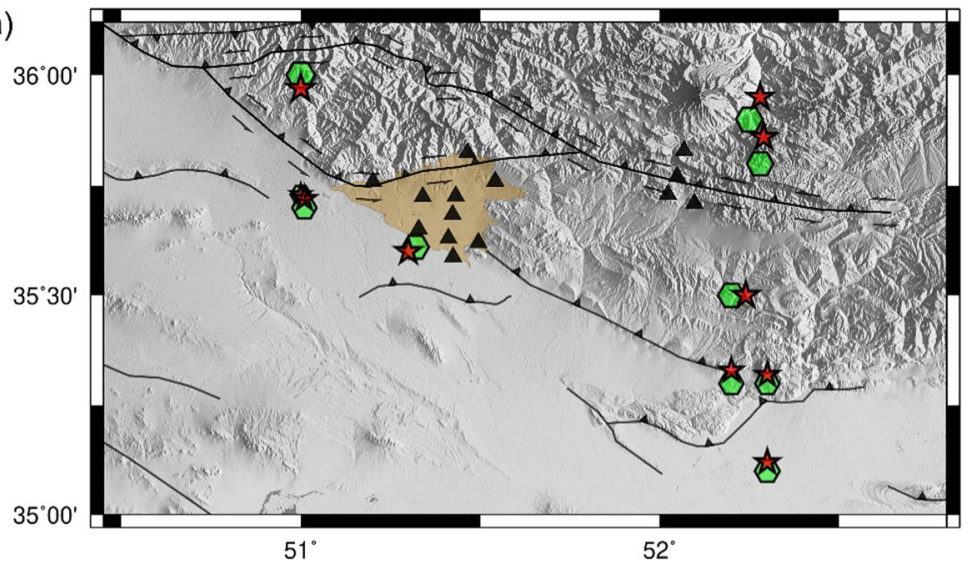

b)

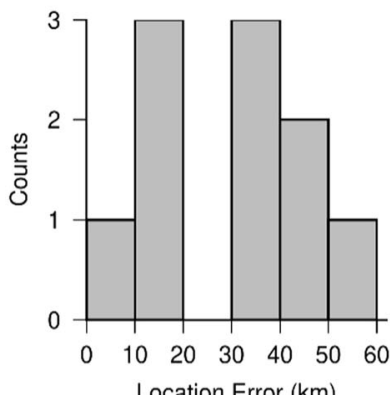

d)

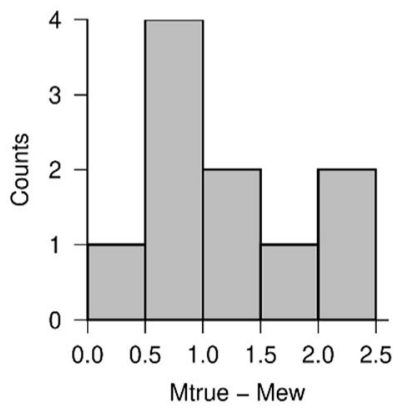

f)

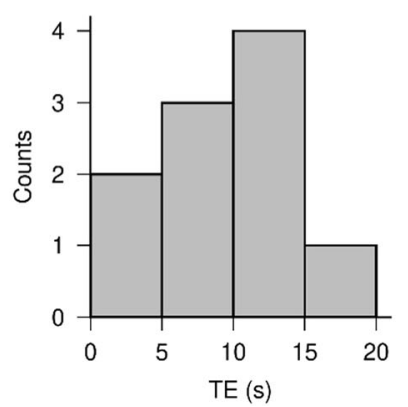

c)

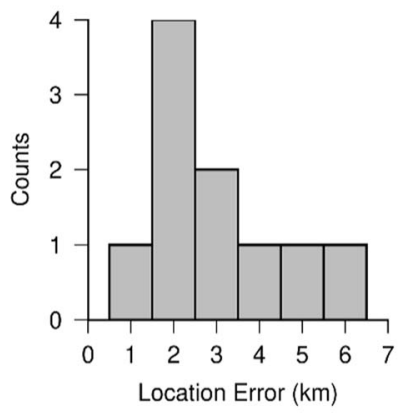

e)
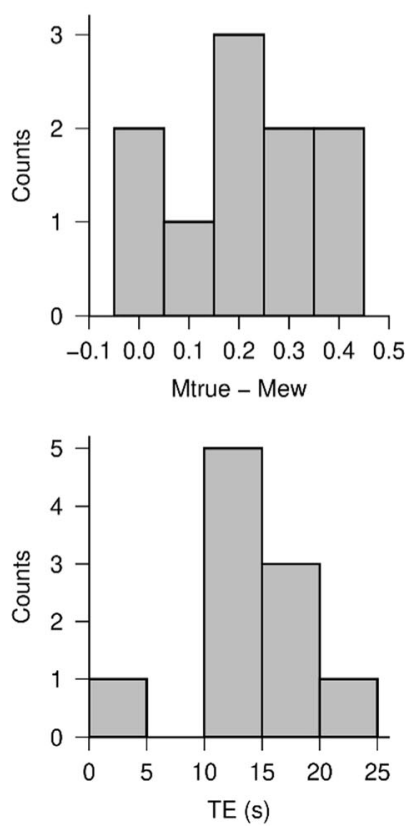

note that the average epicentral distance of the instrumental and historical earthquakes to The Metropolis of Tehran is $\sim 70$ and $\sim 90 \mathrm{~km}$, respectively. Therefore, some problems such as relatively larger epicentral distances of the historical earthquakes to the TDMMO network, in addition to the lack of comprehensive information about source parameters of large historical events, poor distribution and low density of TDMMO network stations, low SNR, and event-station geometry, can lead to great worsening of the results with three 
Table 5 Same as Table 4 but for the analyses based on synthetic data

\begin{tabular}{|c|c|c|c|c|}
\hline $\begin{array}{l}\text { Historical } \\
\text { earthquakes } \\
\text { (year) }\end{array}$ & $\begin{array}{l}\text { Number of } \\
\text { triggered } \\
\text { stations }\end{array}$ & $\begin{array}{l}\text { Error of } \\
\text { location } \\
(\mathrm{km})\end{array}$ & $\begin{array}{l}\text { Error of } \\
\text { magnitude } \\
\text { (unit) }\end{array}$ & $\begin{array}{l}\mathrm{TE} \\
\text { (s) }\end{array}$ \\
\hline \multirow[t]{2}{*}{855} & 3 & 3 & 0.2 & 2 \\
\hline & 3 & 3 & 0.2 & 2 \\
\hline \multirow[t]{2}{*}{864} & 3 & 30 & 1.5 & 8 \\
\hline & 8 & 1 & 0.2 & 11 \\
\hline \multirow[t]{2}{*}{1665} & 3 & 40 & 0.5 & 8 \\
\hline & 6 & 2 & 0.3 & 13 \\
\hline \multirow[t]{2}{*}{958} & 3 & 10 & 1.2 & 7 \\
\hline & 8 & 2 & 0.0 & 11 \\
\hline \multirow[t]{2}{*}{1825} & 3 & 10 & 0.8 & 10 \\
\hline & 6 & 2 & 0.3 & 13 \\
\hline \multirow[t]{2}{*}{743} & 3 & 30 & 2.0 & 10 \\
\hline & 10 & 3 & 0.4 & 15 \\
\hline \multirow[t]{2}{*}{1687} & 3 & 40 & 1.4 & 3 \\
\hline & 9 & 6 & 0.2 & 17 \\
\hline \multirow[t]{2}{*}{1809} & 3 & 15 & 0.5 & 13 \\
\hline & 5 & 5 & 0.1 & 14 \\
\hline \multirow[t]{2}{*}{1830} & 3 & 50 & 2.0 & 13 \\
\hline & 8 & 2 & 0.4 & 15 \\
\hline \multirow[t]{2}{*}{1868} & 3 & 30 & 0.8 & 16 \\
\hline & 10 & 4 & 0.0 & 20 \\
\hline
\end{tabular}

triggered stations. It is obvious that selection of the point source model especially for large events and any errors in modeling of synthetic data generation can lead to incorrect estimations of earthquake parameters by the TDMMO-PRESTo system. Note that with an increase in the number of the triggered stations, as expected, the performance of the system improves significantly (Fig. 6; Table 5).

With the obtained results, we found that the TDMMO-PRESTo system, with the current number and distribution of stations, may not be very useful for EEW purposes and large earthquakes in some cases. Moreover, the next goal of the TDMMO is to increase the number of stations to more than 70 in the near future, which in addition to increasing stations' density will improve the performance of the TDMMO-PRESTo system in the event of a possible large earthquake in Tehran. Since the historical and instrumental seismicity of the study area is concentrated on the southern and eastern parts of Tehran (Fig. 1), we suggest that these new stations be installed and distributed in the vicinity of
Tehran, especially around the Mosha reverse fault, Rey reverse faults, and North Tehran thrust fault, where the occurrence of large earthquakes is imminent. Dense distribution of stations, in the event of a possible devastating earthquake, allows the network to detect the earthquake quickly, and provides fast and reliable estimation of its parameters using only three stations. Therefore, the system will be able to provide more LT to take protective measures before the destructive wave arrives in the region of Tehran.

The overall statistics show that three categories of earthquake scenarios can be considered for The Metropolis of Tehran. The first scenario is related to the historical and instrumental earthquakes coming from the south of Tehran. As for the first scenario, our results show that the 2009 October $17 M_{L} 4.0$ and the $855 M_{s}$ 7.1 Ray earthquakes are the worst-case earthquake scenarios for Tehran which occurred in the vicinity of Rey reverse faults (Figs. 4c and 7a). In these two earthquakes, the TDMMO-PRESTo system provided reliable LT of about 1 to $5 \mathrm{~s}$ for northern and western parts of Tehran. It is worth noting that these two earthquakes are too close to Tehran in order to offer sufficiently large LT to be useful for civil protection purposes in the southern parts of Tehran. However, these obtained LT, as golden seconds, are very useful for taking basic protective measures in the northern and western parts of Tehran, especially in The Metropolis of Karaj, which is situated $50 \mathrm{~km}$ west of Tehran. Furthermore, in other earthquakes that occurred in the vicinity of Parchin fault, the available LT obtained for all parts of Tehran were about 2 to $14 \mathrm{~s}$. It is necessary to note that the selection of the worstcase earthquake scenario is based on an earthquake that has the largest magnitude, the shortest distance, and the minimum LT for The Metropolis of Tehran. We have to emphasize that due to the lack of large instrumental seismic records $(M>6.0)$, the worst-case earthquake scenario in these earthquakes has been selected only by considering the factors of the shortest distance and the minimum LT, and the factor of magnitude has not been taken into account. It is obvious that in case of possible instrumental earthquakes with larger magnitude in each of the study areas, the worst-case earthquake scenario will vary for The Metropolis of Tehran.

The second scenario is based on the earthquakes coming from the east of Tehran. Figure 1 confirmed that the east of Tehran hosts many historical and instrumental earthquakes that occurred in the vicinity of Mosha reverse fault. In this scenario, we observed that, for all of the 
Fig. 7 Same as Fig. 4 but for 10 large historical earthquakes that occurred in the vicinity of Tehran (green hexagons) (a)

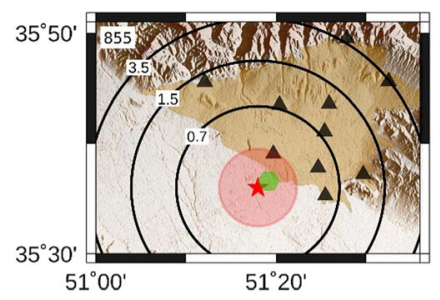

(b)

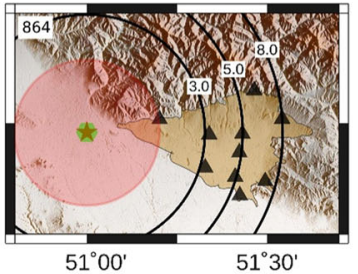

(c)

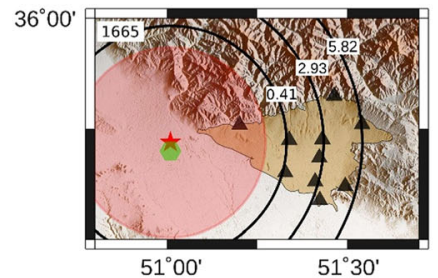

(d)

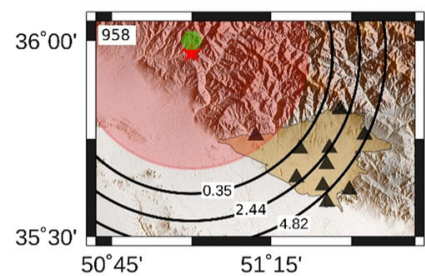

(e)

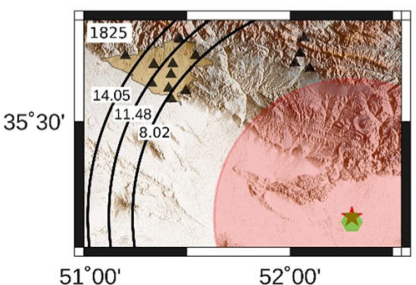

(f)

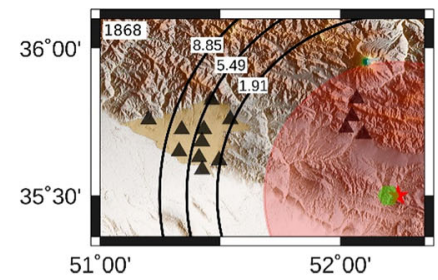

(g)

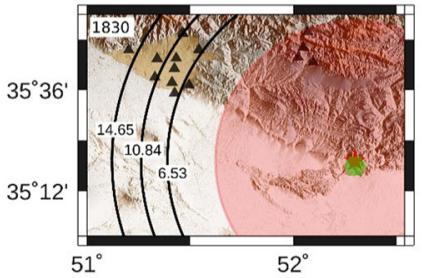

(h)

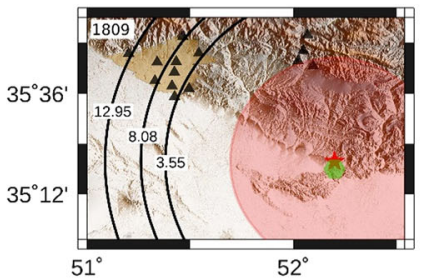

(i)

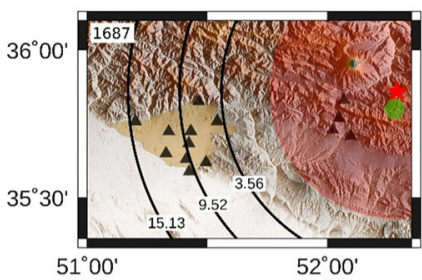

(j)

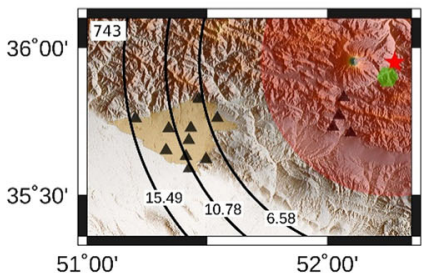

analyzed earthquakes, the system could theoretically provide reliable LT of about 3 to 20s for all parts of Tehran. Moreover, the 2020 May $07 M_{L} 5.0$ and the $743 M_{s} 7.2$ Damavand earthquakes were selected as the worst-case earthquake scenarios for Tehran (Figs. 5 and 7j). Maximum LT of about $15 \mathrm{~s}$ are inferred for these two earthquakes in the western parts of Tehran. The 2020 May 07 $M_{L}$ 5.0 Damavand earthquake is the latest moderate instrumental earthquake that occurred in the vicinity of Tehran, which has increased the concerns about the possibility of a devastating earthquake in Tehran.
The third scenario is related to the earthquakes coming from the west of Tehran. It is worth noting that the six historical and instrumental earthquakes have occurred in the west of Tehran. The 2017 December 20 $M_{L} 5.2$ and the $1665 M_{s} 6.5$ Malard earthquakes are the worst-case earthquake scenarios for Tehran, because of their location and LT (Figs. 4a and 7c). These two earthquakes occurred in the vicinity of North Tehran thrust fault, which have increased the vulnerability of the western and northern parts of Tehran. In these two worst-case earthquake scenarios, the LT of about 1 to $5 \mathrm{~s}$ 
were estimated, which are very useful for taking necessary actions, especially in the eastern parts of Tehran.

The Metropolis of Tehran is known to have high potential for seismic activities, and hosts overpopulation, high-rise buildings, many basic industries and infrastructures, many active faults, large gas-network, and extensive subway lines of the region. It is difficult to present a perfect list of advantages of EEWS in Tehran, but these advantages clearly outweigh the costs. Therefore, we believe that if the only advantage of the TDMMO-PRESTo EEWS in Tehran is the automatic shutdown of the gas-network and the prevention of fires and secondary catastrophe damages of a possible devastating earthquake, this system could play a key role in the reduction of casualties and devastating losses. Due to the expansion of subway lines in Tehran, another key advantage of the system is the slowing down and stopping of high-speed trains before the destructive wave arrives in Tehran. Therefore, depending on the location of the earthquakes, we will have different available LT for The Metropolis of Tehran, which are golden seconds for protective measures such as protection of critical systems and public transportation systems, issuing warnings to fire departments and municipalities, and stopping airport operations.

\section{Conclusions}

In this work, by integrating the TDMMO network and PRESTo software platform, we explored the feasibility and potential of an EEWS in Tehran. In particular, we assessed the performance of the TDMMO-PRESTo system in providing the reliable estimations of earthquake parameters (location and magnitude), as well as the available LT for The Metropolis of Tehran. In this study, three categories of earthquake scenarios were selected based on seismicity on four main active faults: the Mosha reverse fault, the North Tehran thrust fault, and the North and the South Ray reverse faults. Despite the poor distribution of TDMMO network stations, low SNR, and event-station geometry, for three categories of earthquake scenarios, our results show that the TDMMO-PRESTo system is able to provide sufficient and reliable LT of about 1 to $15 \mathrm{~s}$ and maximum LT of about 20s for Tehran. When accompanied by preparation of a population, these available LT would be sufficient to minimize the potential economic and humanitarian consequences of a devastating earthquake in
Tehran. Therefore, an EEWS could potentially assist the population to find a safe place in the LT available if infrastructures required are provided in Tehran.

Acknowledgements The seismic waveforms used in this work come from the Tehran Disaster Mitigation and Management Organization (TDMMO). We used the software Generic Mapping Tools (Wessel et al. 2013, http://gmt.soest.hawaii.edu/) for plots and SAC (Goldstein et al. 2003) for data preprocessing. The authors wish to thank the TDMMO for providing the seismicity records used in this study. We would also like to thank an anonymous reviewer for useful comments and suggestions.

Funding Open access funding provided by Uppsala University.

Open Access This article is licensed under a Creative Commons Attribution 4.0 International License, which permits use, sharing, adaptation, distribution and reproduction in any medium or format, as long as you give appropriate credit to the original author(s) and the source, provide a link to the Creative Commons licence, and indicate if changes were made. The images or other third party material in this article are included in the article's Creative Commons licence, unless indicated otherwise in a credit line to the material. If material is not included in the article's Creative Commons licence and your intended use is not permitted by statutory regulation or exceeds the permitted use, you will need to obtain permission directly from the copyright holder. To view a copy of this licence, visit http://creativecommons.org/licenses/by/4.0/.

\section{References}

Abbassi A, Nasrabadi A, Tatar M, Yaminifard F, Abbassi MR, Hatzfeld D, Priestly K (2010) Crustal velocity structure in the southern edge of the Central Alborz (Iran). J Geodyn 49:6878

Ambraseys NN, Melville CP (1982) A history of Persian earthquakes. Cambridge University Press, Cambridge

Berberian M, Yeats RS (1999) Patterns of historical earthquake rupture in the Iranian Plateau. Bull Seismol Soc Am 89(1): 120-139

Berberian M, Ghoreishi M, Arajang B, Awesh R, Mohajer-Ashjai A (1983) Seismotectonic and earthquake fault hazard investigations in the Tehran region. Geological Survey of Iran. Report No. 56

Colombelli S, Amoroso O, Zollo A, Kanamori H (2012) Test of a threshold-based earthquake early warning using Japanese data. Bull Seismol Soc Am 102:1266-1275

Coutant O (1989) Program of numerical simulation AXITRA. Res. Report LGIT, Grenoble, in French

Goldstein P, Dodge D, Firpo M, Minner L (2003) SAC2000: signal processing and analysis tools for seismologists and engineers. In: Lee WHK, Kanamori H, Jennings PC, Kisslinger C (eds) In Invited contribution to The IASPEI International Handbook of Earthquake and Engineering Seismology. Academic Press, London 
Jackson J, McKenzie D (1984) Active tectonics of the Alpine Himalayan Belt between western Turkey and Pakistan. Geophys J Int 77(1):185-264

Moinfar A, Mahdavian A, Maleki E (1994) Historical and instrumental earthquake data collection of Iran. Publication Iranian Culture. Affairs Inst, Tehran, p 446

Nakamura Y (1988) On the urgent earthquake detection and alarm system (UrEDAS). In: Proceedings of Ninth World Conference on Earthquake Engineering. Tokyo-Kyoto, Japan, vol VII, pp 673-678

Nazeri S, Shomali ZH, Colombelli S, Elia L, Zollo A (2017) Magnitude estimation based on integrated amplitude and frequency content of the initial $\mathrm{P}$ wave in earthquake early warning applied to Tehran, Iran. Bull Seismol Soc Am 107(3):1432-1438

Nowroozi A (2010) Probability of peak ground horizontal and peak ground vertical accelerations at Tehran and surrounding areas. Geophys. 167:1459-1474. https://doi.org/10.1007 /s00024-010-0108-y

Odaka T, Ashiya K, Tsukada S, Sato S, Ohtake K, Nozaka D (2003) A new method of quickly estimating epicentral distance and magnitude from a single seismic record. Bull Seismol Soc Am 93:526-532

Picozzi M, Zollo A, Brondi P, Colombelli S, Elia L, Martino C (2015a) Exploring the feasibility of a nationwide Earthquake Early Warning System in Italy. J Geophys Res Solid Earth 120:2446-2465

Picozzi M, Emolo A, Martino C, Zollo A, Miranda N, Verderame G, Boxberger T, the REAKT Working Group (2015b) Earthquake Early Warning System for schools: a feasibility study in Southern Italy. Seismol Res Lett 86(2A):398-412

Purcaru G, Berckhemer H (1978) A magnitude scale for very large earthquakes. Tectonophysics 49:189-198

Satriano C, Lomax A, Zollo A (2008) Real-time evolutionary earthquake location for seismic early warning. Bull Seismol Soc Am 98(3):1482-1494

Satriano C, Wu YM, Zollo A, Kanamori H (2010) Earthquake early warning: concepts, methods and physical grounds. Soil Dyn Earthq Eng 31(2):106-108
Satriano C, Elia L, Martino C, Lancieri M, Zollo A, Iannaccone G (2011) PRESTo, the Earthquake Early Warning System for Southern Italy: concepts, capabilities and future perspectives. Soil Dyn Earthq Eng 31(2):137-153. https://doi.org/10.1016 /j.soildyn.2010.06.008

Soghrat MR, Ziyaeifar M (2017) Ground motion prediction equations for horizontal and vertical components of acceleration in Northern Iran. J Seismol 21:99-125. https://doi. org/10.1007/s10950-016-9586-4

Tchalenko JS, Braud BJ, Berberian M (1974) Discovery of three earthquake faults in Iran. Nature. 248:661-663

Wessel P, Smith WH, Scharroo R, Luis J, Wobbe F (2013) Generic mapping tools: improved version released, Eos. Trans Am Geophys Union 94(45):409-410

Yaminifard M, Moradi A, Naghavi M (2012) Source parameters of the October 17, 2009 Rey-Tehran earthquake, Mw 4.3. Iran J Geophys 6(3):46-58

Zollo A, Iannaccone G, Lancieri M, Cantore L, Convertito V, Emolo A, Festa G, Gallovič F, Vassallo M, Martino C, Satriano C, Gasparini P (2009) Earthquake Early Warning System in Southern Italy: methodologies and performance evaluation. Geophys Res Lett 36:L00B07. https://doi. org/10.1029/2008GL03668

Zollo A, Amoroso O, Lancieri M, Wu YM, Kanamori H (2010) A threshold-based earthquake early warning using dense accelerometer networks. Geophys J Int 183:963-974

Zollo A, Colombelli S, Elia L, Emolo A, Festa G, Iannaccone G, Martino C, Gasparini P (2014) An integrated regional and onsite Earthquake Early Warning System for Southern Italy: concepts, methodologies and performances. In: Early warning for geological disasters, Adv. Technol. Earth Sci., pp $117-137$

Publisher's note Springer Nature remains neutral with regard to jurisdictional claims in published maps and institutional affiliations. 